\title{
Influence of Age on the Clinical and Prognostic Features of Tetanus in Mali
}

\author{
Mikaïla Kaboré1*, Issa Konaté1,2, Yacouba Cissoko1,2, Jean Paul Dembélée1,2, Mariam Soumaré1, \\ Assetou Fofana1, Dramane Sogoba1, Oumar Magassouba', Hermine Méli' ${ }^{1}$, Abdoulaye Zaré1, \\ Mohamed Aly Cissé1, Bintou Coulibaly¹, Hama Hamidou Issa1, Fodé Kouyaté1, Japhet Dembélé1, \\ Sounkalo Dao1,2,3
}

\author{
${ }^{1}$ Infectious Diseases Department, Point “G” University Teaching Hospital, Bamako, Mali \\ ${ }^{2}$ Faculty of Medicine and Odontostomatology, University of Sciences, Techniques and Technologies of Bamako (USTTB), \\ Bamako, Mali \\ ${ }^{3}$ Serefo Program, University of Sciences, Techniques and Technologies of Bamako (USTTB), Bamako, Mali \\ Email: ^mikailakab@gmail.com
}

How to cite this paper: Kaboré, M., Konaté, I., Cissoko, Y., Dembélé, J.P., Soumaré, M., Fofana, A., Sogoba, D., Magassouba, O., Méli, H., Zaré, A., Cissé, M.A., Coulibaly, B., Issa, H.H., Kouyaté, F., Dembélé, J. and Dao, S. (2021) Influence of Age on the Clinical and Prognostic Features of Tetanus in Mali. International Journal of Clinical Medicine, 12, 77-86 https://doi.org/10.4236/ijcm.2021.123010

Received: January 18, 2021

Accepted: March 15, 2021

Published: March 18, 2021

Copyright (c) 2021 by author(s) and Scientific Research Publishing Inc. This work is licensed under the Creative Commons Attribution International License (CC BY 4.0).

http://creativecommons.org/licenses/by/4.0/

(c) (i) Open Access

\begin{abstract}
Background: The regression of post-vaccination immunity with age exposes elderly subjects to certain infectious diseases, in particular tetanus. The aim was to compare the clinical and prognostic features of tetanus according to the age of patients. Methodology: Analytical study of the files of patients hospitalized for tetanus in the Infectious Diseases Department at Point "G" University Teaching Hospital from 2013 to 2019 with retrospective collection. According to age, three groups of patients were formed: group I ( $<18$ years), group II (18 - 59 years) and group III ( $\geq 60$ years). The study variables were socio-demographic, clinical and prognostic. The One-way ANOVA and Chi-square statistical tests were applied with a significance level $\mathrm{p}=0.05$. Results: In total, 202 cases of tetanus were recorded or $7.3 \%$ of admissions. The mean age was $41.9 \pm 15.6$ years (range, 6 and 85 years) with a sex ratio of 19.2. According to the age grouping, group II was predominant $(79.2 \%)$ followed by group III (14.9\%) with respective mean ages of $39.2 \pm 10.6$ and 67.3 \pm 6.5 and sex ratio of 39 and 29 . Workers $(33.3 \%)$, farmers (25.8\%), traders (19.7\%) and drivers (7.1\%) represented the most important occupations most at risk. Clinically, bad general condition $(\mathrm{p}<0.001)$, trismus $(\mathrm{p}=0.001)$, dysphagia $(p=0.009)$ and complications during hospitalization $(\mathrm{p}=0.028)$ were seen more frequently in group III patients compared to younger ones. From a prognostic point of view, patients in group III were at greater risk to develop a severe form of tetanus $(\mathrm{p}=0.021)$ with higher mortality compared to other age groups $(\mathrm{p}<0.001)$. Conclusion: Tetanus is more prevalent in men. Complications and mortality increase with age. It is important to include booster immunization of adults in existing national programs in order
\end{abstract}


to reduce disease-related morbidity and mortality in this age group.

\section{Keywords}

Tetanus, Elderly, Clinical, Prognosis, Mali

\section{Introduction}

While tetanus has almost disappeared from northern countries because of vaccination and improved hygiene, it remains a significant public health problem in developing countries where immunization programs are insufficiently implemented [1] [2] [3] [4] [5]. The annual incidence of tetanus is estimated at nearly one million cases [5]. The disease burden is very heavy in resource-limited countries [3] [5] [6] [7]. In fact, in 2015, Sub-Saharan Africa recorded 44\% and $36 \%$ of deaths related to neonatal tetanus and that of children and adults respectively in the world [8]. Several studies on tetanus have been carried out in Africa but the main emphasis was on epidemiological and prognostic aspects. And it appears that tetanus mainly affects young adult males [7] [9]-[17]. In this sense, Dao et al., in Mali in 2009 found a hospital frequency of $5.9 \%$ with a sex ratio of 2.17 and an average age of 39 years [9]. As for Sondo et al., in 2018 in Burkina Faso, the hospital frequency of tetanus was estimated at $2.6 \%$ with a sex ratio of 4.1 and an average age of 29.2 years [15].

Tetanus is a bacterial disease caused by Clostridium tetani, a spore-forming, cosmopolitan germ, which secretes a potent neurotoxin. C. tetani spores enter the body through contaminated skin or tissue lesions and sometimes through puncture wounds [2] [3]. It is a serious disease, however preventable by vaccination [3] [5] [6].

It is well known that immunity to the tetanus vaccine acquired in childhood decreases with age, thus exposing adults to the disease [6] [18] [19]. However, there is no vaccine booster program for adults other than women during pregnancy [6]. How significant is the morbidity and mortality from tetanus depending on the patient's age? The influence of age on clinical signs and the fate of tetanus patients in our countries have not yet been addressed, justifying this study that the objective was to perform a comparison of the clinical and prognostic features of tetanus according to the groups of ages.

\section{Patients and Methods}

This was a retrospective and analytical study using hospital data from January 2013 to December 2019, i.e. a period of seven (7) years. The Infectious Diseases Department of the Point "G" University Teaching Hospital in Bamako was the study setting. It's the referral service for infectious pathologies in Mali with an inpatient capacity of 30 beds in addition to a non-functional Intensive Care Unit. Severe tetanus cases requiring intensive care are transferred and managed 
in the Intensive Care Department.

All complete records of patients hospitalized for tetanus during the period were included except those patients who died within 24 hours of hospitalization.

The diagnosis was just clinical. Tetanus was defined by a set of signs namely: trismus with the presence of Armengaud's captive tongue depressor sign; generalized or localized contracture; the presence or absence of a gateway; the presence or absence of spontaneous paroxysm, painful or caused by noise or light, the presence or absence of dysphagia [20] [21].

The management consisted of:

- hospitalization with neurosensory isolation and restriction of food intake by the oral route;

- administration of muscle relaxants drugs to fight against muscle spasms;

- administration of antibiotics and tetanus immunoglobulins;

- the application of a vaccination protocol by tetanus toxoid;

- the gateway treatment when it was found.

Three groups of patients were formed according to their age:

- Group I: corresponded to patients under 18 years-old. At this age, the immunity to the tetanus vaccine acquired at birth remains protective;

- Group II: for ages between 18 and 59 years-old;

- Group III: for patients at least 60 years-old.

The study variables were grouped into socio-demographic variables (age, sex, occupation, place of residence); clinical variables (gateway, type of lesion, clinical signs) and development variables (outcome of hospitalization, length of stay).

Regarding clinical signs, the change in clinical state corresponded to a deterioration in the subject's overall state of health [22].

We assessed the clinical severity of tetanus using the Dakar score [23]. Tetanus was considered benign for a Dakar score between 0 and 1 . It was moderate if the score varied between $2-3$ and severe when the score was between 4 and 6 .

Data collected was entered using Epidata entry 3.1 software and analyzed with Statistical Package for Social Science (SPSS) version 22 software.

A descriptive analysis first made it possible to appreciate the distribution of the values of variables as well as the parameters of central tendencies. Then, statistical tests were applied with a significance level $p=0.05$. The 1-way ANOVA test was used to compare means in the three age groups. The chi-square test made it possible to compare the proportions. Fisher's test was used when the theoretical cell size was less than 5. Analyzes were performed on anonymized data collected as part of routine patient care. We obtained an authorization from the Head of Department for the data using and the conduct of the study. No further investigation was conducted.

\section{Results}

\subsection{Main Features}

During the period, 202 patients were hospitalized for tetanus out of a total of 
2,782 admissions, for a hospital frequency of $7.3 \%$.

The mean age of the patients was $41.9 \pm 15.6$ years with ranges of 6 years and 85 years. Men represented $95 \%$ of the sample $(n=192)$ avec a sex ratio of 19.2 . The mean age of the men was $42.6 \pm 14.9$ years and that of the women was 27.6 \pm 21.5 years $(\mathrm{p}<0.001)$. Most of the patients lived in couple $(73.8 \%)$ and resided in the city of Bamako (70.3\%). The occupations most exposed to tetanus were manual workers (33.3\%), farmers (25.8\%), traders $(19.7 \%)$ and drivers $(7.1 \%)$. Before admission to the Infectious Diseases Department, patients were first seen and cared for in another hospital (32.7\%) or a referral health center $(19.8 \%)$. The results are shown in Table 1.

Figure 1 illustrates the distribution of patient by demographic data. In terms of numbers, patients in group II (18 - 59 years old) were the most represented (79.2\%) followed by those in group III (60 years and over) (14.9\%); and their sex ratio was largely in favor of men, respectively 39 and 29.

Table 1. General characteristics of the sample.

\begin{tabular}{|c|c|}
\hline Variables & n (\%) \\
\hline \multicolumn{2}{|l|}{ Patient sex $(n=202)$} \\
\hline Male & $192(95.0)$ \\
\hline Female & $10(5.0)$ \\
\hline \multicolumn{2}{|l|}{ Marital status $(n=202)$} \\
\hline In couple & $149(73.8)$ \\
\hline Single life & $53(26.2)$ \\
\hline \multicolumn{2}{|l|}{ Place of residence $(n=202)$} \\
\hline Bamako & $142(70.3)$ \\
\hline Outside Bamako & $60(29.7)$ \\
\hline \multicolumn{2}{|l|}{ Occupation $(n=198)$} \\
\hline Worker & $66(33.3)$ \\
\hline Farmer & $51(25.8)$ \\
\hline Trader & $39(19.7)$ \\
\hline Driver & $14(7.1)$ \\
\hline Official & $11(5.6)$ \\
\hline Students & $6(3.0)$ \\
\hline Housewives & $6(3.0)$ \\
\hline Other informal sectors & $5(2.5)$ \\
\hline \multicolumn{2}{|l|}{ Provenance $(n=202)$} \\
\hline Hospital & $66(32.7)$ \\
\hline CsREF* $^{*}$ & $40(19.8)$ \\
\hline Home & $36(17.8)$ \\
\hline Private clinic & $28(14.1)$ \\
\hline $\operatorname{CSCOM}^{* *}$ & $18(9.1)$ \\
\hline
\end{tabular}

${ }^{*}$ CsREF: Referral Health Center; ${ }^{*}$ CSCOM: Community Health Center. 


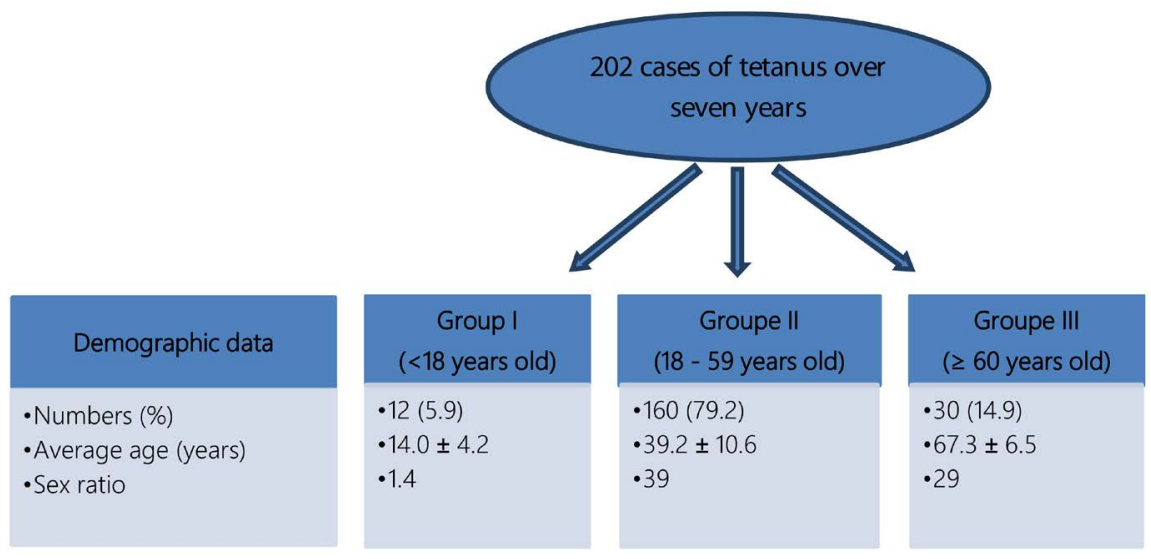

Figure 1. Demographic data of patients by age group.

\subsection{Age Influence on Clinical Characteristics of Patients}

Clinically, the general condition of the patients gradually deteriorated with age. On admission, bad clinical condition was observed more frequently in group III patients $(\mathrm{p}<0.001)$. It was the same for trismus $(\mathrm{p}=0.001)$, dysphagia $(\mathrm{p}=$ $0.009)$ and the occurrence of complications during hospitalization $(p=0.028)$. Systolic blood pressure $(\mathrm{p}=0.007)$, diastolic blood pressure $(\mathrm{p}=0.028)$, pulse ( $\mathrm{p}$ $=0.029)$, and body mass index $(\mathrm{p}=0.001)$ were higher in group III patients compared to groups II and I. However, paroxysm, respiratory distress, incubation and invasion times were not significantly influenced by patient age. Table 2 shows the distribution of clinical signs by age.

\subsection{Age Influence on the Prognosis of Tetanus}

Table 3 presents elements for assessing the prognosis of patients according to the three age groups. On admission, patients in group III were at greater risk to develop a severe form of tetanus $(\mathrm{p}=0.021)$. Patient mortality increased with age and was higher in group III compared to younger patients $(\mathrm{p}<0.001)$. Age did not have a statistically significant influence on patient length of stay $(\mathrm{p}=$ $0.116)$.

\section{Discussion}

Tetanus remains a worrying pathology in the referral Department for Infectious Diseases in Mali. It represented $7.3 \%$ of all infectious pathologies treated during the period. This frequency varies according to the African studies between 5.3\% and $11.8 \%$ [9] [14] [24].

Tetanus in Africa remains the preserve of young adults and males [3] [11] [14] [24] [25] [26] and that was the case in our study. The mean age of our patients was 41.9 years with a sex ratio largely predominant for men $(20$ men for a woman). This observation could be explained by the anti-tetanus immunization policy for girls and pregnant women during antenatal consultations, which provides them with long-term protection compared to men [2] [7] [27]. On the other hand, tetanus is more often seen in elder women in developed countries, 
Table 2. Distribution of clinical data according to age groups.

\begin{tabular}{|c|c|c|c|c|}
\hline Variables & $\begin{array}{c}\text { Groupe I } \\
\mathrm{n}(\%)\end{array}$ & $\begin{array}{c}\text { Groupe II } \\
\mathrm{n}(\%)\end{array}$ & $\begin{array}{c}\text { Groupe III } \\
\text { n (\%) }\end{array}$ & $\mathbf{P}$ \\
\hline \multicolumn{5}{|l|}{ Clinical condition } \\
\hline Well & $9(75.0)$ & $115(71.9)$ & $9(30.0)$ & \\
\hline $\mathrm{Bad}$ & $3(25.0)$ & $45(28.1)$ & $21(70.0)$ & $<0.001$ \\
\hline \multicolumn{5}{|l|}{ Trismus } \\
\hline Absent & $2(16.7)$ & $2(1.2)$ & $0(0)$ & \\
\hline Present & $10(83.3)$ & $158(98.8)$ & $30(100)$ & 0.001 \\
\hline \multicolumn{5}{|l|}{ Paroxysm } \\
\hline Absent & $2(16.7)$ & $33(20.6)$ & $3(10.0)$ & \\
\hline Present & $10(83.3)$ & $127(79.4)$ & $27(90.0)$ & 0.386 \\
\hline \multicolumn{5}{|l|}{ Dysphagia } \\
\hline Absent & $10(83.3)$ & $111(69.4)$ & $13(43.3)$ & \\
\hline Present & $2(16.7)$ & $49(30.6)$ & $17(56.7)$ & 0.009 \\
\hline \multicolumn{5}{|l|}{ Respiratory distress } \\
\hline Absente & $12(100)$ & $151(94.4)$ & $28(93.3)$ & \\
\hline Presente & $0(0)$ & $9(5.6)$ & $2(6.7)$ & 0.674 \\
\hline \multicolumn{5}{|l|}{ Complications } \\
\hline Absent & $7(58.3)$ & $77(48.1)$ & $7(23.3)$ & \\
\hline Present & $5(41.7)$ & $83(51.9)$ & $23(76.7)$ & 0.028 \\
\hline \multicolumn{5}{|c|}{ Mean values \pm standard deviation } \\
\hline Incubation time (days) & $8.8 \pm 3.6$ & $13.7 \pm 18.3$ & $14.0 \pm 17.4$ & 0.692 \\
\hline Invasion time (days) & $1.5 \pm 1.1$ & $1.7 \pm 1.1$ & $1.8 \pm 1.2$ & 0.656 \\
\hline Systolic blood pressure ${ }^{\star}$ & $114.0 \pm 13.8$ & $124.4 \pm 17.9$ & $137.3 \pm 26.6$ & 0.007 \\
\hline Diastolic blood pressure & $70.5 \pm 12.3$ & $79.7 \pm 11.7$ & $84.7 \pm 21.3$ & 0.028 \\
\hline Pulse $(\mathrm{ppm})^{\star \star}$ & $98.1 \pm 16.4$ & $97.1 \pm 17.7$ & $106.4 \pm 15.9$ & 0.029 \\
\hline $\mathrm{FR}(\mathrm{cpm})^{* * *}$ & $28.7 \pm 9.3$ & $26.1 \pm 6.0$ & $28.4 \pm 7.0$ & 0.113 \\
\hline $\mathrm{BMI}\left(\mathrm{kg} / \mathrm{m}^{2}\right)$ & $17.9 \pm 7.4$ & $22.5 \pm 3.4$ & $24.7 \pm 4.0$ & 0.001 \\
\hline
\end{tabular}

${ }^{*}$ Blood pressure unity in $\mathrm{mmHg} ;{ }^{* *} \mathrm{ppm}=$ beats per minute; ${ }^{* * *} \mathrm{cpm}=$ cycle per minute.

Table 3. Distribution of prognostic data according to age groups.

\begin{tabular}{ccccc}
\hline Variables & $\begin{array}{c}\text { Groupe I } \\
\mathbf{n}(\%)\end{array}$ & $\begin{array}{c}\text { Groupe II } \\
\mathbf{n}(\%)\end{array}$ & $\begin{array}{c}\text { Groupe III } \\
\mathbf{n}(\%)\end{array}$ & P \\
\hline $\begin{array}{c}\text { Severity of tetanus (Dakar score) } \\
\text { Benign (score 0 - 1) }\end{array}$ & $4(33.3)$ & $48(30.0)$ & $3(10.0)$ & \\
Moderate (score 2 - 3) & $7(58.3)$ & $94(58.8)$ & $18(60.0)$ & 0.991 \\
Severe (score 4 - 6) & $1(8.3)$ & $18(11.2)$ & $9(30.0)$ & 0.021 \\
Outcome of hospitalization & & & & \\
Death & $1(8.3)$ & $70(43.8)$ & $25(83.3)$ & $<0.001$ \\
Living & $11(91.7)$ & $90(56.3)$ & $5(16.7)$ & \\
Length of stay (days) & $15.3 \pm 7.7$ & $11.2 \pm 9.5$ & $8.3 \pm 13.3$ & 0.116 \\
\hline
\end{tabular}


men being protected by vaccination during required military service [19] [28] [29] [30]. Workers (33.3\%), farmers (25.8\%), traders (19.7\%) and drivers (7.1\%) were the socio-professional groups most exposed to tetanus in our study. These are professional activities with a risk of injury, especially when protective measures are not sufficiently applied. They are most commonly exercised by men, making them even more susceptible to tetanus than women [1] [7] [18]. Before admission to the Infectious Diseases department, more than half of our patients came from a referral health center or hospital, for etiological diagnostic problems or technical support. Some patients have even been taken care of beforehand by traditional healers. All of this could contribute to delaying diagnosis and treatment, which are aggravating factors for tetanus in our context [14] [31].

Patients in group III (over 60 years of age) tended to have an altered clinical condition on admission compared to younger patients. In addition, the symptomatology was more evident in these elderly patients through the presence of trismus, the manifestation of dysphagia and the occurrence of complications during hospitalization. A tendency for blood pressure to rise and pulse rate to increase was also noted in those over 60 years of age. These findings have been made by other authors who confirm the vulnerability of this age group compared to younger patients [24].

Aging is synonymous with carrying comorbidities such as diabetes, arterial hypertension, cancer, etc. [24] which are at risk of decompensation due to Clostridium infection and can thus contribute to worsening the clinical condition and prognosis. Although an incubation period of less than seven (7) days and an invasion period of less than 48 hours are generally considered to be indicative of a badprognosis [3] [5] [18], in our study there was no statistically significant difference for these two parameters depending on the age of the patients. The same was true of the paroxysm and respiratory distress. The small sample size in our study could explain these results.

In many countries, the lack of material and human resources in our hospitals contributes to justifying high mortality among tetanus patients [5] [7]. However, age is also a determinant of morbidity and mortality [3]. The aging of people is accompanied by senescence of the anti-tetanus immune system [3] [32] [33] [34] [35] justifying an increase in the incidence of tetanus cases but also the frequency of severe and fatal forms with age [3] [18] [36]. In our study, people over 60 were at greater risk of dying from tetanus than those younger. This result corroborates that of Tanon et al., in the Republic of Côte d'Ivoire in 2017, who found that those over 60 were three times more at risk of dying from tetanus than the younger ones [17]. In Lagos, in 2005, a study on hospital mortality from tetanus came to the same conclusion [25]. Another Nigerian study in 2009 concluded that the only factor for survival during tetanus was young age [26]. There is great interest in stepping up disease prevention measures in favor of the elderly who are moreover vulnerable to other diseases due to age. We would like to emphasize here the interest in introducing the booster or catch-up tetanus vaccination in adults in order to limit the burden of the disease [34] [36]. But 
beyond age, several other factors are often cited as contributing to patient mortality in our context, in particular the virulence of the Clostridium strain in question, the severity of the clinical signs, the insufficiency of materiel resources for intubate and ventilate cases of respiratory failure due to dysautonomia, as poverty limits patients' access to intensive care [5] [7].

The main limitation of our study concerns the incompleteness in the registration of patient records. This limit is frequent in retrospective studies.

\section{Conclusion}

Although vaccination is the best way to avoid tetanus, it remains a major public health problem with regard to the morbidity and mortality caused. In our context, tetanus is found much more in adult men and has a bad prognosis in the elderly. There is an interest in taking age into account in the clinical and prognostic assessment of tetanus cases. To reduce the burden of tetanus in adults, it is imperative to expand booster immunization to these vulnerable age groups through national immunization programs to ensure universal health coverage.

\section{Acknowledgements}

Our thanks to the entire team of the Infectious Diseases Department of Point "G" University Teaching Hospital.

\section{Conflicts of Interest}

The authors declare no conflicts of interest regarding the publication of this paper.

\section{References}

[1] Fan, Z., Zhao, Y., Wang, S., et al. (2019) Clinical Features and Outcomes of Tetanus: A Retrospective Study. Infection and Drug Resistance, 12, 1289-1293. https://doi.org/10.2147/IDR.S204650

[2] World Health Organization (2017) Tetanus Vaccines: WHO Position Paper-February 2017. The Weekly Epidemiological Record, 92, 53-76.

[3] Yen, L.M. and Thwaites, C.L. (2019) Tetanus. The Lancet, 393, 1657-1668. https://doi.org/10.1016/S0140-6736(18)33131-3

[4] Shah, B. (2018) A Review on Pharmacological Management of Generalised Tetanus. General Medicine, 6, 311. https://doi.org/10.4172/2327-5146.1000311

[5] Ingole, K., Mundhada, S. and Powar, R. (2016) Tetanus in Developing Countries: A Review and Case Series. International Journal of Applied Research, 2, 556-560.

[6] Dalal, S., Samuelson, J., Reed, J., et al. (2016) Tetanus Disease and Deaths in Men Reveal Need for Vaccination. Bulletin of the World Health Organization, 94, 613-621. https://doi.org/10.2471/BLT.15.166777

[7] Woldeamanuel, Y.W., Andemeskel, A.T., Kyei, K., et al. (2016) Case Fatality of Adult Tetanus in Africa: Systematic Review and Meta-Analysis. Journal of the Neurological Sciences, 368, 292-299. https://doi.org/10.1016/j.jns.2016.07.025

[8] Kyu, H.H., Mumford, J.E., Stanaway, J.D., et al. (2017) Mortality from Tetanus be- 
tween 1990 and 2015: Findings from the Global Burden of Disease Study 2015. BMC Public Health, 17, 179. https://doi.org/10.1186/s12889-017-4111-4

[9] Dao, S., Oumar, A.A., Maiga, I., et al. (2009) Tétanos en milieu hospitalier à Bamako, Mali. Médecine Tropicale, 69, 485-487.

[10] Traoré, A.M., Coulibaly, I., Dabo, G., et al. (2017) Tétanos associés aux accidents de la voie publique dans le service des maladies infectieuses du CHU du Point G, Bamako, Mali. Médecine Santé Tropicale, 27, 176-181.

[11] Aba, T., Kra, O., Ehui, E., et al. (2011) Aspects cliniques et évolutifs du tétanos lié aux soins dans le service de référence du CHU d'Abidjan. Bulletin de la Société de Pathologie Exotique, 104, 38-41. https://doi.org/10.1007/s13149-010-0092-6

[12] Manga, N.M., Dia N.M., Ndour, C.T., et al. (2009) Le tétanos de la femme en âge de procréer à la clinique des maladies infectieuses de Dakar. Médecine et Maladies infectieuses, 102, 901-905. https://doi.org/10.1016/j.medmal.2008.10.011

[13] Ndour, C.T., Soumare, M., Mbaye, S.D., et al. (2005) Tetanus Following Intramuscular Injection in Dakar: Epidemiological, Clinical and Prognostic Features. Dakar Medical, 50, 160-163.

[14] Ossibi Ibara, B.R., Mabiala Babela, J.R., Atipo Ibara Ollandzobo, L., et al. (2017) Tetanus: Epidemiological and Clinical Aspects and Factors Associated with Death at the University Hospital of Brazzaville, Congo. Médecine et Santé Tropicale, 27, 411-414. https://doi.org/10.1684/mst.2017.0746

[15] Sondo, K.A., Zoungrana, J., Savadogo, M., et al. (2018) Tetanus at Yalgado Ouedraogo University Hospital Center in Ouagadougou from 2000 to 2014. Journal of Infectious Diseases and Therapy, 6, Article ID: 1000358.

[16] Tanon, A.K., Eholié, S.P., Coulibaly-Dacoury, C. and Ehui, E. (2004) Morbidité et mortalité du tétanos dans le service des maladies infectieuses et tropicales d'Abidjan (1985-1998). Bulletin de la Société de Pathologie Exotique, 97, 283-287.

[17] Tanon, A.K., Doumbia, A. and Coffie, P.A. (2017) Current Prognostic Factors of Tetanus in Abidjan: 2005-2014. Journal of Microbiology Infectious Diseases, 7, 125-131. https://doi.org/10.5799/jmid.367529

[18] Khajehdehi, P. and Rezaian, G.R. (1998) Tetanus in the Elderly: Is It Different from That in Younger Age Groups? Gerontology, 44, 172-175. https://doi.org/10.1159/000022004

[19] Toker, I., Kilıc, T.Y., Kose, S., et al. (2017) Tetanus Immunity Status among Adult Trauma Patients in an ED. Turkish Journal of Emergency Medicine, 17, 95-98. https://doi.org/10.1016/j.tjem.2017.02.001

[20] Bae, C. and Bourget, D. (2020) Tetanus. StatPearls Publishing, Treasure Island. http://www.ncbi.nlm.nih.gov/books/NBK459217

[21] World Health Organization (2018) Tetanus [Internet]. WHO, Geneva. https://www.who.int/news-room/fact-sheets/detail/tetanus

[22] Andrès, E. (2009) Altération de l'état général: Une terminologie non médicale, mais utile pour le grand public. Presse Médicale, 38, 1035-1036. https://linkinghub.elsevier.com/retrieve/pii/S0755498209002000 https://doi.org/10.1016/j.lpm.2009.04.004

[23] Vachon F. (1975) IV congrès international sur le tétanos (Dakar 6-11 Avril 1975). Médecine et Maladies Infectieuses, 6, 310-311.

[24] Attinsounon, C.A., Fortes Déguénonvo L., Cissoko, Y. et al. (2014) Coût direct de la prise en charge hospitalière et facteurs prédictifs de mauvais pronostic du tétanos à Dakar (Sénégal). Médecine d Afrique Noire, 66, 411-416. 
[25] Ojini, F.I. and Danesi, M.A. (2005) Mortality of Tetanus at the Lagos University Teaching Hospital, Nigeria. Tropical Doctor, 35, 178-181. https://doi.org/10.1258/0049475054620806

[26] Ajose, F.O.A. and Odusanya, O.O. (2009) Survival from Adult Tetanus in Lagos, Nigeria. Tropical Doctor, 39, 39-40. https://doi.org/10.1258/td.2008.080116

[27] Aba, Y.T., Cissé, L., Abalé, A.K., et al. (2016) Morbidité et mortalité du tétanos des nouveau-nés et des enfants dans les Centres hospitaliers universitaires d'Abidjan, Côte d'Ivoire (2001-2010). Bulletin de la Société de Pathologique Exotique, 109, 172-179. https://doi.org/10.1007/s13149-016-0483-4

[28] Mahieu, R., Reydel, T., Maamar, A., et al. (2017) Admission of Tetanus Patients to the ICU: A Retrospective Multicentre Study. Annals of Intensive Care, 7, Article No. 112. https://doi.org/10.1186/s13613-017-0333-y

[29] Aubry, P. and Gaüzère, B.A. (2019) Tétanos: Actualités 2018. Médecine Tropicale, $1-9$.

[30] Nakajima, M., Aso, S., Matsui, H., et al. (2018) Clinical Features and Outcomes of Tetanus: Analysis Using a National Inpatient Database in Japan. Journal of Critical Care, 44, 388-391. https://doi.org/10.1016/j.jcrc.2017.12.025

[31] Diallo Mbaye, K., Fortes Déguénonvo, L., Amona, M., et al. (2014) Itinéraire thérapeutique des malades admis pour tétanos au service des maladies infectieuses du CHNU de Fann. Médecine et Maladies Infectieuses, 44, 38. https://doi.org/10.1016/S0399-077X(14)70148-9

[32] Alkan, İ., Öztürk, C.E., Çalişkan, E. and Akar, N. (2019) Investigation of Tetanus Antibody Levels in Adults. Duzce Medical Journal, 21, 98-102.

[33] Mizuno, Y., Yamamoto, A., Komiya, T., et al. (2014) Seroprevalence of Tetanus Toxoid Antibody and Booster Vaccination Efficacy in Japanese Travelers. Journal of Infection and Chemotherapy, 20, 35-37. https://doi.org/10.1016/j.jiac.2013.11.003

[34] Weinberger, B., Schirmer, M., Matteucci Gothe, R., et al. (2013) Recall Responses to Tetanus and Diphtheria Vaccination Are Frequently Insufficient in Elderly Persons. PLoS ONE, 8, e82967. https://doi.org/10.1371/journal.pone.0082967

[35] Weinberger, B. (2018) Vaccines for the Elderly: Current Use and Future Challenges. Immunity \& Ageing, 15, 3. https://doi.org/10.1186/s12979-017-0107-2

[36] Isono, H., Miyagami, T., Katayama, K., et al. (2016) Tetanus in the Elderly: The Management of Intensive Care and Prolonged Hospitalization. Internal Medicine, 55, 3399-3402. https://doi.org/10.2169/internalmedicine.55.7131 